\title{
Extension of Direct Displacement-Based Design to Plan-Asymmetric RC Frame Buildings
}

\author{
Alessandro Paparo ${ }^{1}$, Luca Landi $^{2}$ and Pier Paolo Diotallevi ${ }^{2}$ \\ 1. Earthquake Engineering and Structural Dynamics Laboratory, Swiss Federal Institute of Technology of Lausanne, Lausanne 1015, \\ Switzerland \\ 2. Department of Civil, Environmental and Materials Engineering, University of Bologna, Bologna 40136, Italy
}

\begin{abstract}
The object of this paper is the evaluation of the seismic response of reinforced concrete frames designed according to the DDBD (direct displacement-based design) approach. The great part of research works about DDBD has been dedicated to planar frames, but recently also some proposals for 3D structures have been presented, in particular for wall structures. This paper will give a further contribution to the extension of the procedure for the case of plan-asymmetric RC (reinforced concrete) frames. The extended methodology is aimed at accounting for the floor rotations on the basis of a given lateral strength distribution along the plan. The procedure was applied to two plan-asymmetric RC frames, characterized by the same geometry but different lateral strength distributions along the plan. The seismic behavior of the designed frames was studied by adopting a fiber model and by performing pushover and nonlinear dynamic analyses.
\end{abstract}

Key words: Direct-displacement-based design, pushover analysis, non-linear dynamic analysis, plan-asymmetric structures.

\section{Introduction}

In the last years a lot of research has been aimed to mitigate the problems of current force-based design. In particular, several design approaches have been proposed for designing structures in order to achieve a specified deformation state under the design earthquake [1]. These approaches are characterized by the assumption of displacement as fundamental design parameter, and they are known as Displacement-Based Design procedures. When the design method does not require iterations, it is called DDBD (direct displacement-based design). The approach proposed by Priestley $[2,3]$ is a Direct Displacement-Based procedure characterized by the use of secant stiffness to maximum displacement. The method is based on the characterization of a substitute structure and on the use of highly damped displacement spectra. This approach

Corresponding author: Luca Landi, assistant professor, research fields: nonlinear seismic analysis of structures, seismic design procedures, seismic isolation and supplemental damping, probabilistic approaches, and vulnerability of existing buildings. E-mail:1.landi@unibo.it. has then been studied and applied with reference to different structural typologies [4-9].

Torsional response of asymmetric structures responding to seismic excitation is complex. Since the response is in general inelastic, it involves both the strength and stiffness eccentricity, as well as the torsional mass inertia. DDBD initially did not include the torsional response. Analytical studies in recent years by Paulay [10], Castillo [11] and Beyer [12] have enabled some guidelines for the torsional response of inelastic eccentric structures, taking care also with the effective rotational stiffness and the strength eccentricity. The problem of the torsional response has been deepened for cantilever wall buildings. For such buildings the mentioned studies have shown that the torsional inertia plays an important role in modifying the structural response of both unrestrained and restrained systems.

In light of these studies the present paper proposes an extension of the design procedure for the case of plan-asymmetric frame buildings. The proposed procedure requires the assumption of a given lateral 
strength distribution along the plan [13]. The goal of the methodology is the correction of the design base shear to account for the effects of the asymmetry: with varying this characteristic, the distribution and the intensity of the total base shear change. The procedure was then applied to reinforced concrete frame structures. In particular two structures characterized by six storeys and different plan-irregularities were analyzed. The differences between these two structures regard the "a priori" assumption of the lateral strength distribution along the plan. In one case the same lateral strength was considered for the plane frames in the transversal direction. In this case a strength eccentricity was obtained due to the asymmetric position of the plane frames. In the other case the lateral strength distribution of the plane frames in the transversal direction was defined in order to obtain zero strength eccentricity.

Nonlinear static and dynamic analyses were then carried out with the purpose to validate the algorithm. The fiber model implemented in the OpenSees software [14, 15] was used for the nonlinear analyses. The time-history analyses were performed considering a group of seven earthquake records consistent with the design spectrum in a range of periods from zero to the corner period, equal about to four seconds.

\section{General Design Procedure}

The direct displacement-based design of the structures under study was performed according to the criteria and rules proposed by Priestley et al. [6] with reference to reinforced concrete frame structures. In a first phase, for a given design displacement, the design base shear is derived through the definition of the substitute structure. From strain or drift limits, defined depending on design seismic intensity, it is possible to obtain the design displacement of each storey $i\left(\Delta_{i}\right)$ using the following proposed relationship:

$$
\Delta_{i}=\omega_{\theta} \theta_{c} H_{i} \frac{4 H_{n}-H_{i}}{4 H_{n}-H_{1}}
$$

where, $\theta_{c}$ is the storey drift limit, $\omega_{\theta}$ is a reduction factor which accounts for higher mode amplification, $n$ is the number of storeys, $H_{i}$ is the height of the storey from the base and $H_{n}$ is the roof height. The design displacement of the substitute structure $\left(\Delta_{d}\right)$ can then be determined from the displacements of the storeys:

$$
\Delta_{d}=\sum_{i=1}^{n}\left(m_{i} \Delta_{i}^{2}\right) / \sum_{i=1}^{n}\left(m_{i} \Delta_{i}\right)
$$

where, $m_{i}$ is the mass of the storey $i$. Equivalent mass $\left(m_{e}\right)$ and effective height $\left(H_{e}\right)$ of the substitute structure are given by:

$$
\begin{gathered}
m_{e}=\sum_{i=1}^{n}\left(m_{i} \Delta_{i}\right) / \Delta_{d} \\
H_{e}=\sum_{i=1}^{n}\left(m_{i} \Delta_{i} h_{i}\right) / \sum_{i=1}^{n}\left(m_{i} \Delta_{i}\right)
\end{gathered}
$$

The ductility demand of the substitute structure is $\mu$ $=\Delta_{d} / \Delta_{y}$. The yield displacement $\Delta_{y}$ can be calculated once it is known the yield drift $\theta_{y}$ as $\Delta_{y}=\theta_{y} H_{e}$. It has been shown [6] that yield drift depends mainly on geometry and not on strength. Various expressions have been provided for $\theta_{y}$. In particular, for reinforced concrete frames $\theta_{y}=0.5 \varepsilon_{y} L_{b} / h_{b}$, where $L_{b}$ and $h_{b}$ are beam length and depth respectively, and $\varepsilon_{y}$ is the yield strength of reinforcement steel. For RC frames the equivalent viscous damping may be evaluated as follows:

$$
\xi_{\text {eq }}=0.05+C_{3}\left(\frac{\mu-1}{\mu \pi}\right)
$$

where, $C_{3}$ is a coefficient dependent on the hysteretic response of the structure. This coefficient can vary from 0.1 to 0.7 according to the behaviour of the different structural types. For reinforced concrete frame buildings $C_{3}$ can be assumed equal to 0.565 [6]. The effective period $T_{e}$ at maximum displacement is obtained as a function of design displacement from the displacement spectrum associated with the equivalent viscous damping calculated with Eq. (5). The effective stiffness of the substitute structure and the design base shear of the structure are given by:

$$
\begin{gathered}
K_{e}=4 \pi^{2} m_{e} / T_{e}^{2} \\
V_{B}=K_{e} \Delta_{d}
\end{gathered}
$$


The base shear force is distributed to the floor levels in proportion to the product of mass and displacement. For high-rise frame buildings, $10 \%$ of base shear is additionally applied at roof level to reduce higher mode effect:

$$
F_{i}=F_{t}+0.9 V_{B}\left(m_{i} \Delta_{i}\right) / \sum_{i=1}^{n}\left(m_{i} \Delta_{i}\right)
$$

where, $F_{t}=0.1 V_{B}$ at the roof and $F_{t}=0$ at all other levels. The building under these forces is then analyzed using a simplified method based on equilibrium conditions [6]. Flexural capacity of beams is calculated considering design values of material properties larger than characteristic ones according to $f_{c e}^{\prime}=1.3 f^{\prime}{ }_{c}$ and $f_{y e}^{\prime}=1.1 f^{\prime}$. The columns are designed in order not to exceed the elastic limit under seismic action, and hence capacity design criteria have to be applied.

\section{Procedure for Plan-Asymmetric RC Frame Structures}

Structures with asymmetry in plan are subjected to torsional rotations as well as translations in seismic response. Paulay [10] has shown that for structures responding inelastically to seismic excitation, it is important not only the centre of mass and the centre of stiffness, but also the centre of strength. The eccentricity of the centre of stiffness $\left(e_{R}\right)$ from the centre of mass and the eccentricity of the centre of strength $\left(e_{V}\right)$ can be found as follows (Fig. 1):

$$
\begin{array}{r}
e_{R X}=\frac{\sum_{i=1}^{n} K_{z i} x_{i}}{\sum_{i=1}^{n} K_{z i}} ; e_{R Z}=\frac{\sum_{j=1}^{m} K_{x j} z_{j}}{\sum_{j=1}^{m} K_{x j}} \\
e_{V X}=\frac{\sum_{i=1}^{n} V_{z i} x_{i}}{\sum_{i=1}^{n} V_{z i}} ; e_{V Z}=\frac{\sum_{j=1}^{m} V_{x j} z_{j}}{\sum_{j=1}^{m} V_{x j}}
\end{array}
$$

where, $K_{z i}$ and $K_{x j}$ are element stiffness in the $\mathrm{Z}$ and $\mathrm{X}$ directions respectively, $x_{i}$ and $z_{j}$ are measured from the centre of mass and $V_{Z i}$ and $V_{X j}$ are the design base shear strengths for elements in the $\mathrm{Z}$ and $\mathrm{X}$ directions respectively.

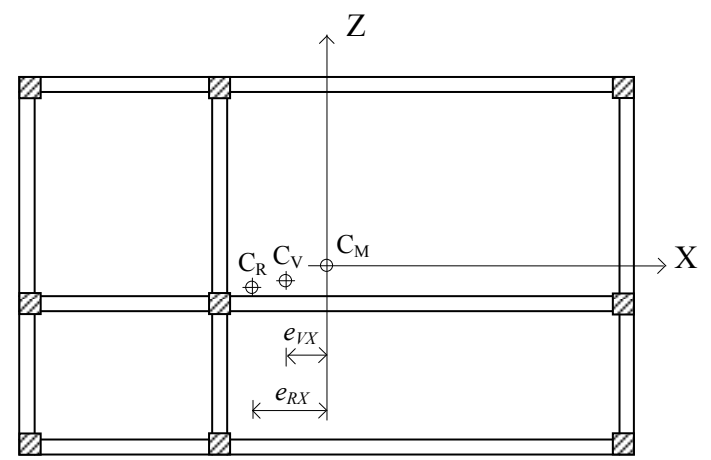

Fig. 1 Example of frame structure asymmetric in plan.

Maximum response displacements of structures with stiffness eccentricity, with or without strength eccentricity, can be calculated as the sum of direct $\left(\Delta_{Z M}\right)$ and torsional components of displacements. For response in the $\mathrm{Z}$ direction:

$$
\Delta_{Z i}=\Delta_{Z M}+\theta\left(x_{i}-e_{V X}\right)
$$

In Eq. (11) it was used the strength eccentricity $e_{V}$ and not the stiffness eccentricity $e_{R}$ as in the elastic design. In addition, the twist angle $\theta$ to be considered comes from the total building strength in the direction under study, in this case $V_{B Z}$ :

$$
\theta=\frac{V_{B Z} \cdot e_{R X}}{J_{R, e f f}}
$$

The effective rotational stiffness $J_{R, e f f}$ in Eq. (12) could be calculated as follow:

$$
\begin{aligned}
& J_{R, e f f}=\frac{1}{\mu} \sum_{i=1}^{n} K_{e l, Z i}\left(x_{i}-e_{R X}\right)^{2}+ \\
& +\sum_{j=1}^{m} K_{e l, X j}\left(z_{j}-e_{R Z}\right)^{2}
\end{aligned}
$$

In Eq. (13), the ductile rotational stiffness $J_{R, \text { eff }}$ is modified from the elastic rotational stiffness, dividing the frame stiffness in the direction considered by the system ductility $\mu$. The elastic stiffness is used for the elements perpendicular to the direction considered, since only the frames parallel to the direction considered are expected to be subjected to significant ductility demand.

Priestley et al. [6] have presented some suggestions for the design. In particular two criteria could be followed. The first one considers the possibility to eliminate or minimize the problem. For example when 
the plan layout of the lateral force resisting elements is unsymmetrical, it may be possible to eliminate strength eccentricity, allocating different base shear between the different elements. Note that with this approach there will still be a torsional component of response despite the zero strength eccentricity, due to the possible stiffness eccentricity. A second approach consists of modifying the design displacement in order to account for torsion. In this case the most common design situation will be that design displacements are governed by drift limits. So the code drift limit will be applied to the frame with the greatest displacement including torsional effects and the other elements will have a smaller design displacement.

This paper deepens the aspect of plan-asymmetry for RC frame structures and proposes an iterative procedure in order to account for the eccentricity. The methodology requires the assumption of a given lateral strength distribution along the plan. The steps of the procedure are illustrated in the following:

(1) The first problem is that the total base shear is unknown, so it is impossible to find the twist angle directly. In order to avoid this problem, initially the system ductility $\mu$ and the base shear $V_{B}$ of the whole structure in the $\mathrm{Z}$ and $\mathrm{X}$ directions are derived assuming that the structure is plan-symmetric;

(2) Then, it is possible to obtain the stiffness eccentricity and the strength eccentricity from Eqs. (9) and (10). Using Eqs. (12) and (13), the twist angle $\theta$ and the effective rotational stiffness $J_{R, \text { eff }}$ are found from the total building strength in the direction considered (for example $V_{B Z}$ );

(3) The most common design situation will be that design displacements are governed by code drift limits. In these cases the most flexible frame governs the design procedure. The most flexible frame will have the design displacement $\Delta_{d}$ (now called $\Delta_{i, c r}$ ). Rearranging Eq. (11) allows determining the displacement of the centre of mass $\Delta^{\prime}{ }_{Z M}$ in the first iteration:

$$
\Delta_{Z M}^{\prime}=\Delta_{i, c r}-\theta\left(x_{i, c r}-e_{V X}\right)
$$

The displacements for the other frames will be found using Eq. (11);

(4) At this point it is possible to check if the different frames have yielded, comparing the displacements of the frames with the corresponding yield displacements. If some frames have not yielded, in the subsequent iteration their stiffness will not be reduced considering the system ductility;

(5) From the new value of the displacement of the centre of mass a new system ductility $\mu^{\prime}=\Delta^{\prime}{ }_{Z M} / \Delta_{y}$ and a new damping ratio $\xi_{\text {eq }}$ could be found using Eq. (5). Then it is possible to calculate a new damped spectrum and a new value of the effective period $T_{e}{ }_{e}$ as a function of displacement $\Delta^{\prime}{ }_{Z M}$;

(6) Using Eq. (7) new values of base shear for the whole structure and for the single frames are obtained. This calculation is performed taking care if the single frames have an elastic or plastic behaviour. If the frames have an elastic behaviour their base shear is recalculated in proportion to the displacement on the basis of the elastic stiffness. Hence the new value of total base shear $V^{\prime}{ }_{B Z}$ is determined as the sum of the values of base shear of each frame;

(7) With this base shear $V_{B Z}^{\prime}$ it is possible to start a new iteration from step (2). The iterations continue until convergence is reached, and the variation of base shear between subsequent iterations becomes negligible. At every iteration it is important to check if each frame has yielded and to know which are the values of lateral stiffness to be reduced. In general it is better that in the considered direction all frames have yielded since it means that the structure is torsionally effective.

If the structure is characterized by plan irregularity in one single direction, the procedure is simpler. Firstly, it is possible to find the base shear in the direction characterized by plan regularity. Then, it is possible to perform the design in the other direction. It was verified that the procedure does converge rapidly and the base shear becomes stable after three or four iterations. 
The Fig. 2 visualizes the iterative procedure for a case with plan irregularity in one single direction: firstly, the frames in the $\mathrm{X}$ direction, that is the direction which does not present irregularity, are designed. Then, the $\mathrm{Z}$ direction is studied: assuming initially plan regularity also in this direction, the displacement-based design procedure is applied. Only at this stage a first eccentricity, in terms of strength and stiffness, is calculated. Subsequently, the effective rotational stiffness and the twist angle are calculated. With all these values, it is possible to start with a first iteration which accounts for the different displacements of the three frames. The procedure continues until convergence, which is generally reached after three of four iterations. In each iteration, the determination of the base shear is performed after checking whether the frames have yielded or not.

\section{Structures under Study}

The procedure described above was applied to design the structures under study (Fig. 3), which are
$\mathrm{RC}$ frame buildings characterized by two spans in the $\mathrm{X}$ direction, one span in the $\mathrm{Z}$ direction and six storeys.

Two different configurations, characterized by different distributions of the lateral strength of the frames in the $\mathrm{Z}$ direction, were studied. In the first one all the three frames are assumed to have the same strength. As a consequence, the strength eccentricity and the stiffness eccentricity are not equal to zero. In the second configuration, instead, the strength distribution is defined in order to have zero strength eccentricity. Because of the same yield displacements of the three frames, in this case also the stiffness eccentricity is equal to zero. The first structure is called $\mathrm{EV}$ (equal lateral strengths), the latter DV (different lateral strengths).

Assumed mechanical properties of materials are: concrete cylinder strength equal to $30 \mathrm{Mpa}$ and steel yield strength equal to $450 \mathrm{Mpa}$. The non-factored gravity loads are: dead load equal to $5 \mathrm{kN} / \mathrm{m}^{2}$ and live load equal to $2 \mathrm{kN} / \mathrm{m}^{2}$. Adopted dimensions of beams in the $\mathrm{X}$ direction are: width equal to $350 \mathrm{~mm}$ and depth
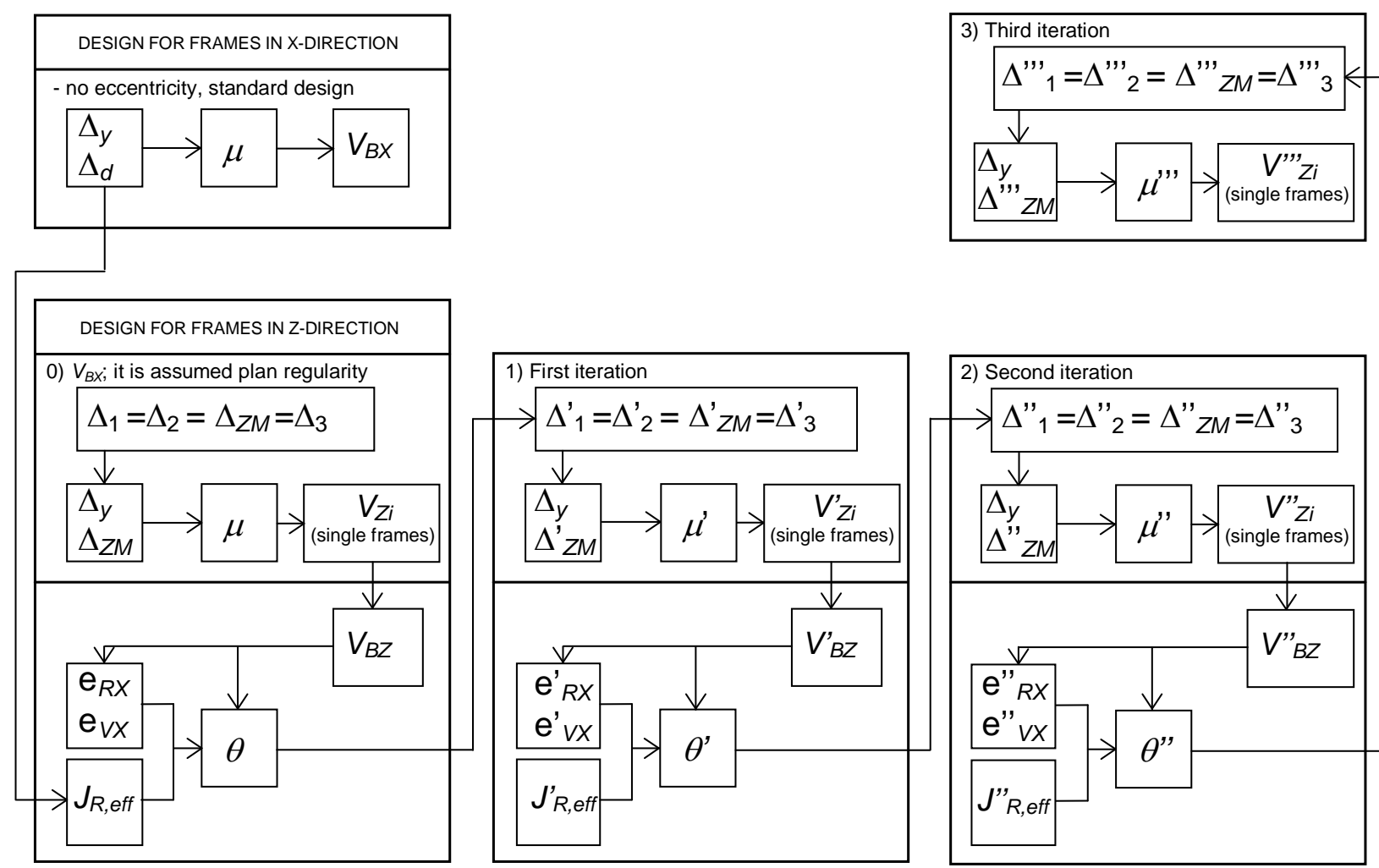

Fig. 2 Iterative procedure for a structure with plan irregularity in one single direction. 

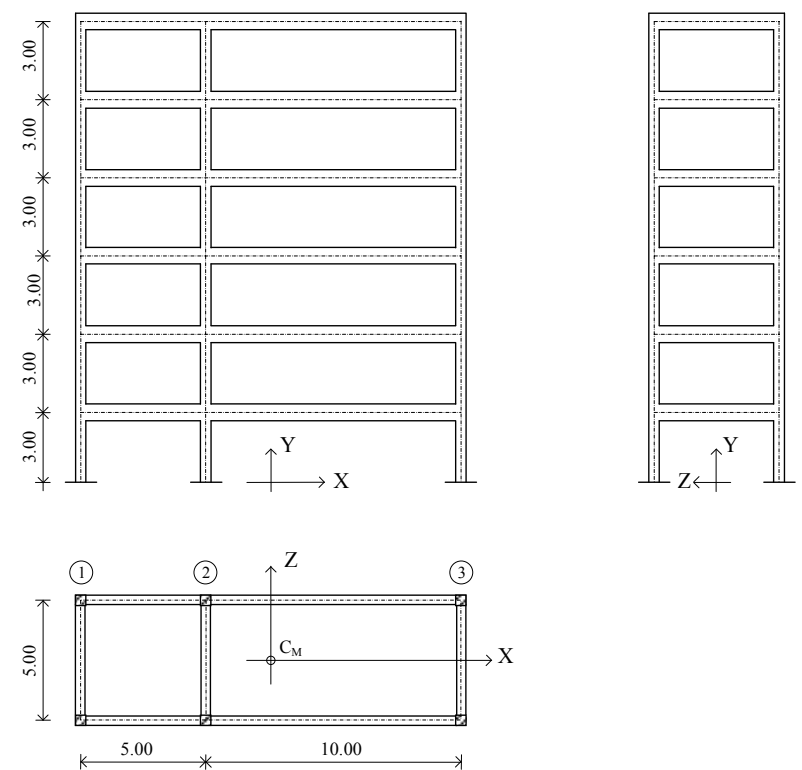

Fig. 3 Considered structural configuration (dimensions in m).

equal to $650 \mathrm{~mm}$. The beams in the $\mathrm{Z}$ direction are characterized by a depth equal to $550 \mathrm{~mm}$. Adopted dimensions of columns are: width and depth equal to $400 \mathrm{~mm}$. The three frames in the $\mathrm{Z}$ direction are called frame 1, frame 2 and frame 3, as it is shown in Fig. 3.

The buildings are considered to be located in a high seismicity region characterized by a maximum causative earthquake of magnitude $M_{w}=7$ at the distance of about $10 \mathrm{~km}$. The design elastic 5\% damped displacement spectrum is characterized by a corner period of $4.25 \mathrm{~s}$ and a corresponding displacement of $726 \mathrm{~mm}$. A design drift limit equal to 0.025 is assumed to be correlated to the considered seismic intensity level. The EV structure presents a plan irregularity and a strength eccentricity. After the iterative procedure an increase of the total base shear of $27 \%$ is obtained (Tables 1 and 2). Furthermore, after the iterations the structure becomes more resistant, and consequently less ductile. Due to this increase of strength, the period of the structure reduces by $20 \%$ and the effective damping varies from $13.3 \%$ to $11.9 \%$. The DV structure, instead, does not show strength eccentricity, nor stiffness eccentricity. So it is not necessary to perform iterations. In this case the total base shear does not increase.
Table 1 Design parameters for the structures under study.

\begin{tabular}{ccccc}
\hline Structure & design drift & $H_{e}(\mathrm{~m})$ & Total $m_{e}\left(\mathrm{kNs}^{2} / \mathrm{m}\right)$ & $\Delta_{y}(\mathrm{~mm})$ \\
\hline EV & 0.025 & 12.7 & 213.6 & 142 \\
DV & 0.025 & 12.7 & 213.6 & 142 \\
\hline
\end{tabular}

Table 2 Design parameters for the structures under study during the iterative procedure.

\begin{tabular}{ccccccc}
\hline \multicolumn{2}{c}{ Structure iteration } & $\Delta_{d}(\mathrm{~mm})$ & $\mu$ & $\xi_{e q}(\%)$ & $T_{e}(\mathrm{~s})$ & $V_{\text {Base }}(\mathrm{kN})$ \\
\hline $\mathrm{EV}$ & 0 & 265 & 1.86 & 13.3 & 2.29 & 432 \\
& 1 & 227 & 1.60 & 11.8 & 1.87 & 559 \\
& 2 & 230 & 1.62 & 11.9 & 1.90 & 547 \\
& 3 & 230 & 1.62 & 11.9 & 1.90 & 548 \\
& 4 & 230 & 1.62 & 11.9 & 1.90 & 549 \\
$\mathrm{DV}$ & 0 & 265 & 1.86 & 13.3 & 2.29 & 432 \\
\hline
\end{tabular}

\section{Nonlinear Model and Performed Analyses}

Nonlinear analyses were carried out in order to assess the performance of the structures under study. The OpenSees software $[14,15]$ was used for the nonlinear analyses. This computer program allows to study the structure with distributed plasticity finite elements characterized by a fibre modelling of the control sections. A bilinear stress-strain relationship with hardening ratio equal to 0.005 was adopted for the steel fibres. A constitutive law which includes the effect of confinement due to stirrup and the stiffness degradation due to cyclic loading was considered for the concrete.

Different types of behaviour were adopted for the cover concrete and the concrete core: in the first case the effect of confinement was neglected, in the second case it was included according to the model proposed by Scott et al. [16]. Gravity loads were applied on the beams in the $\mathrm{X}$ direction.

The performance of the structures was evaluated by means of nonlinear static and dynamic analyses. Nonlinear dynamic analyses were performed using a group of seven earthquake records [17]. The considered design spectrum is the one proposed by Faccioli et al. [18]. The average displacement spectrum of the considered ground motions (Fig. 4) is characterized by increasing ordinates up to the corner period of the design spectrum, equal to $4.25 \mathrm{~s}$. 

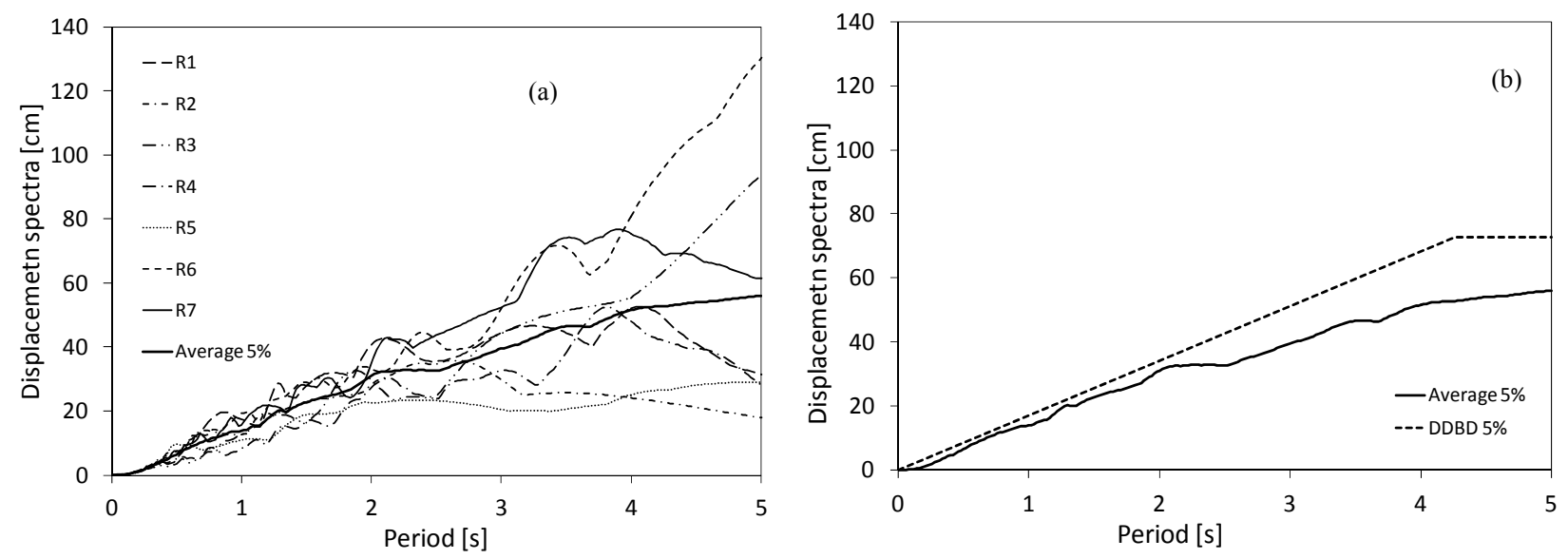

Fig. 4 The average displacement spectrum of the considered ground motions: (a) Displacement spectra of the considered ground motions for $\xi=5 \%$; (b) comparison between average displacement spectrum and design spectrum.

All the ground motions were scaled, in order that the average ordinate of their damped displacement spectrum related to the effective period of the examined structure was equal to the corresponding design value. According to this criterion all the records were scaled to a peak ground acceleration $\mathrm{PGA}=0.575$ g. The ground motions were applied in the $\mathrm{Z}$ direction. The damping was introduced in the model for nonlinear dynamic analyses as proportional to the tangent stiffness.

\section{Results of Analyses}

Pushover analyses were carried out for every single frame in the $\mathrm{Z}$ direction of the EV and DV structures considering lateral forces proportional to the external forces assumed during the design procedure (Eq. (8)). The capacity curves (Fig. 5) were determined in order to compare the calculated lateral strength distribution along the plan with the one assumed in the design phase. For the EV structure, the three capacity curves are similar, and the equal distribution of the base shear assumed in the design is respected. For the DV structure the ratios between the lateral strength of the different frames are approximately similar to the design values. This is consistent with the design assumption to have zero strength eccentricity. The design values of the ratio of the strength of the frames 2 and 3 to the strength of the frame 1 are, respectively,
1.2 and 1.37 while the same values obtained from pushover curves at a displacement equal to $100 \mathrm{~mm}$ are 1.16 and 1.34 .

The results of nonlinear dynamic analyses are illustrated in the Figs. 6 and 7 for the EV structure and in the Figs. 8 and 9 for the DV structure. In general the following results have been compared: the predictions found using the proposed method to account for the plan-asymmetry of the structure (DDBD), the results of the nonlinear dynamic analyses for each single earthquake record (R1, R2, R3, R4, R5, R6 and R7), their average values and their average values plus or minus one standard deviation.

By examining the results relative to the EV structure, it is possible to observe a quite good correspondence between the average diagrams of maximum displacements along the height obtained from the analyses and those assumed in the design (Fig. 6). The displacements obtained with nonlinear dynamic analyses are slightly lower than the design ones.

It is possible to see that for the upper levels the average values from the seismic analyses plus one standard deviation are similar to the design values, in particular for the frame 3, which is located in the flexible side of the structure. At the lower storeys the average values from the seismic analyses are similar to the design values. 

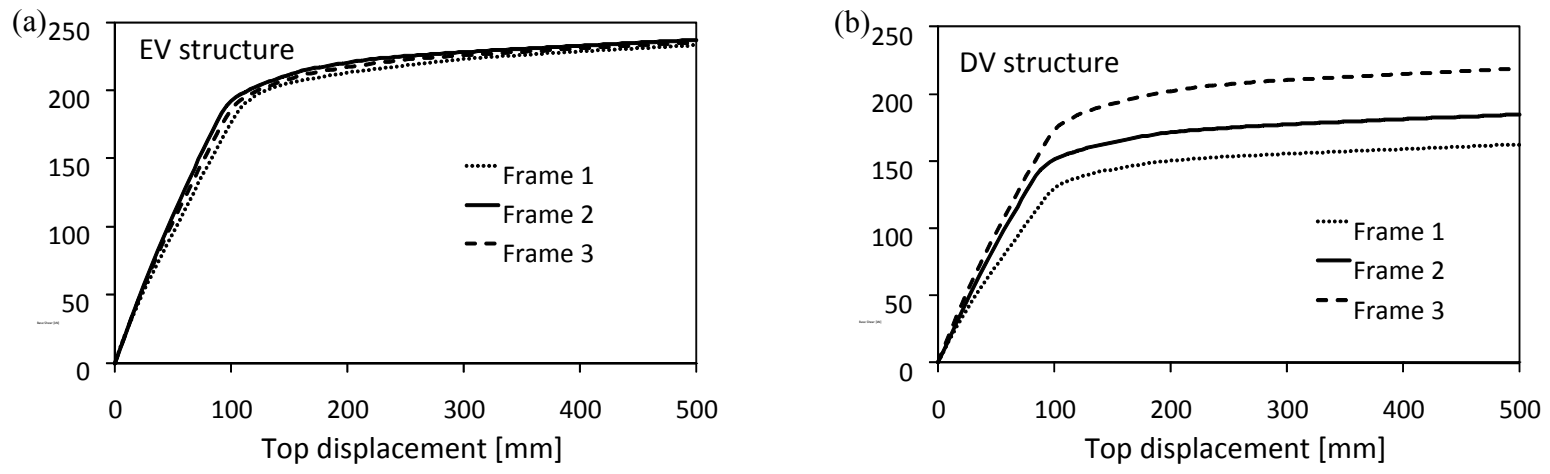

Fig. 5 Push over curves for the frames 1, 2 and 3: (a) the EV structure; (b) DV structure.
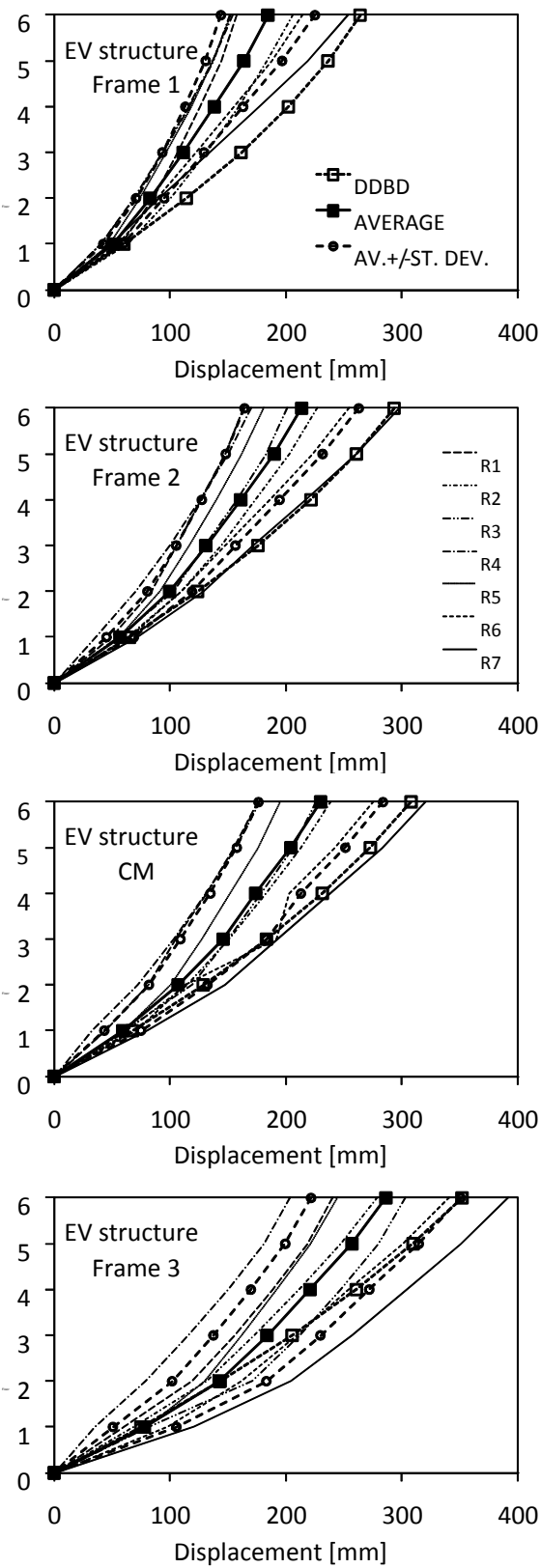
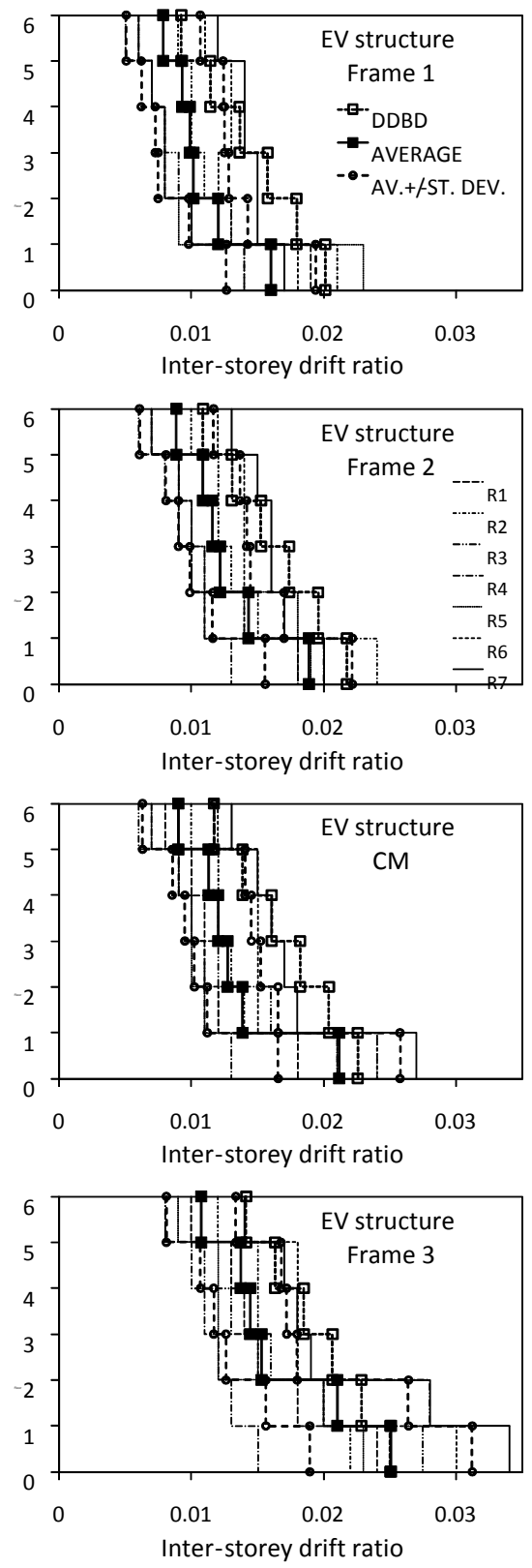

Fig. 6 Horizontal floor displacements and inter-storey drifts for the frames of the EV structure. 
The results regarding the inter-storey drifts show trends similar to those observed for the diagrams of maximum displacement along the height. It is possible to see that for the frame 3 at the first storey the average values plus one standard deviation are slightly larger than the design drift limit, and they are equal about 3\%. The envelope along the plan of the maximum displacements from nonlinear dynamic analyses, normalized to the displacement of the centre of mass, is shown in Fig. 7 for all the floors of the EV structure. It is possible to notice a good correspondence between results from analyses and design, especially in terms of floor rotation.

As observed previously, also in Fig. 7 the average values from seismic analyses for all the frames and for the $\mathrm{CM}$ are slightly lower than the design ones, in particular at the upper storeys. This may be related to the slightly larger values of lateral strength obtained for the frames in comparison with the design.

Also for the DV structure, as for the EV one, the average values from seismic analyses of maximum displacements at the roof (Fig. 8) are characterized by a quite good correspondence with the design ones. The average values from the analyses plus one standard deviation are similar to the design values.

At the lower storeys the average values from the analyses are more close to the design values and the average values plus one standard deviation are slightly larger. By comparing the top displacements obtained for the two structures, there are not significant differences. For the DV structure, in comparison with the $\mathrm{EV}$ one, the top displacement at the centre of mass is similar, at frame 3 is slightly lower and at frame 1 is slightly larger. The results regarding the inter-storey drifts of the DV structure (Fig. 8) show trends similar to those of the maximum displacements.

Fig. 9 shows the envelope along the plan of the maximum displacements obtained from the analyses for all the floors of the DV structure. It is possible to observe, as expected from design, that floor rotations obtained from the analyses are very little. Similar considerations as for Fig. 7 can be made with reference to the values of displacements from the seismic analyses and from the design.
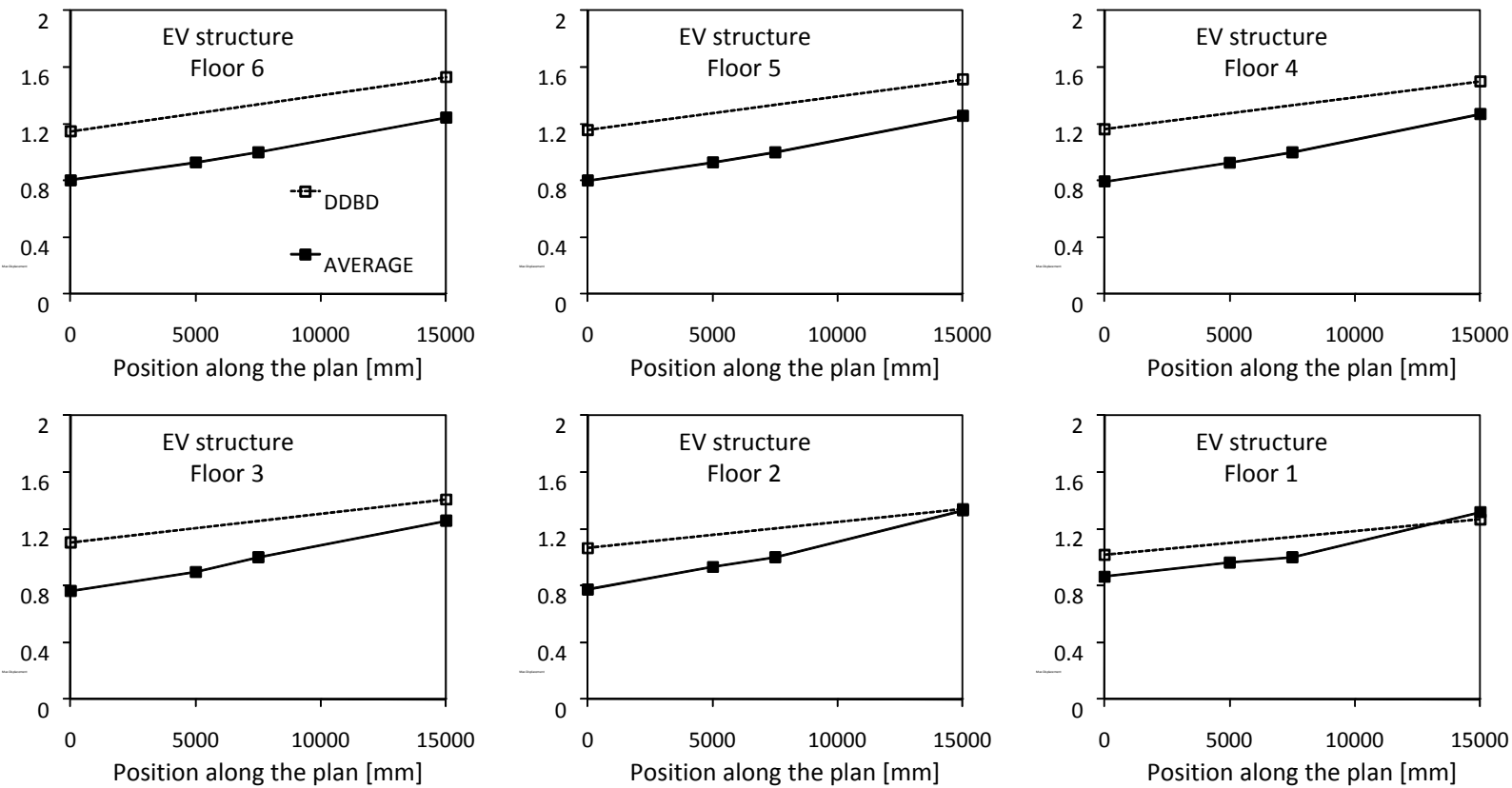

Fig. 7 Envelope of maximum horizontal displacements along the plan for the EV structure. 

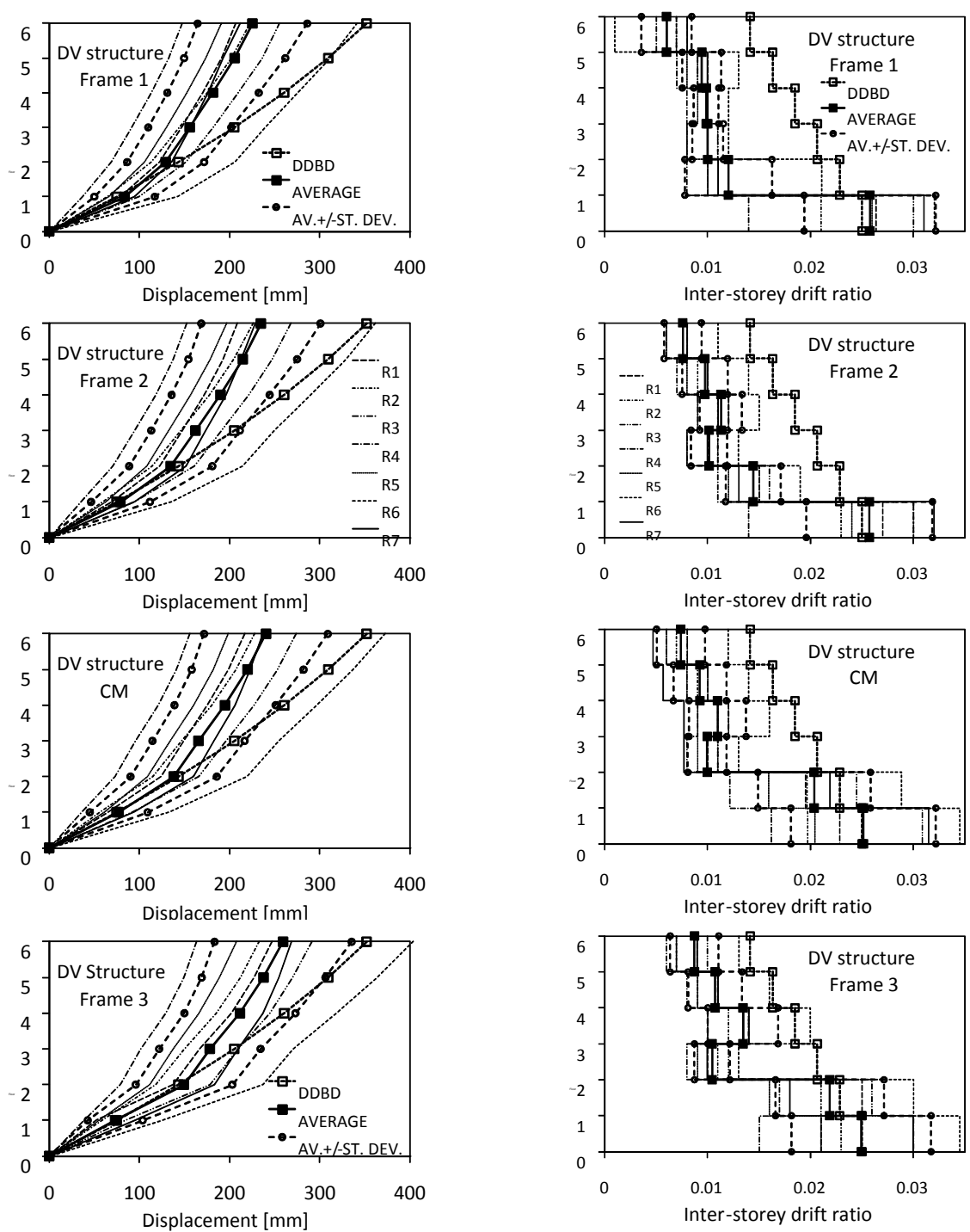

Fig. 8 Horizontal floor displacements and inter-storey drifts for the frames of the DV structure.
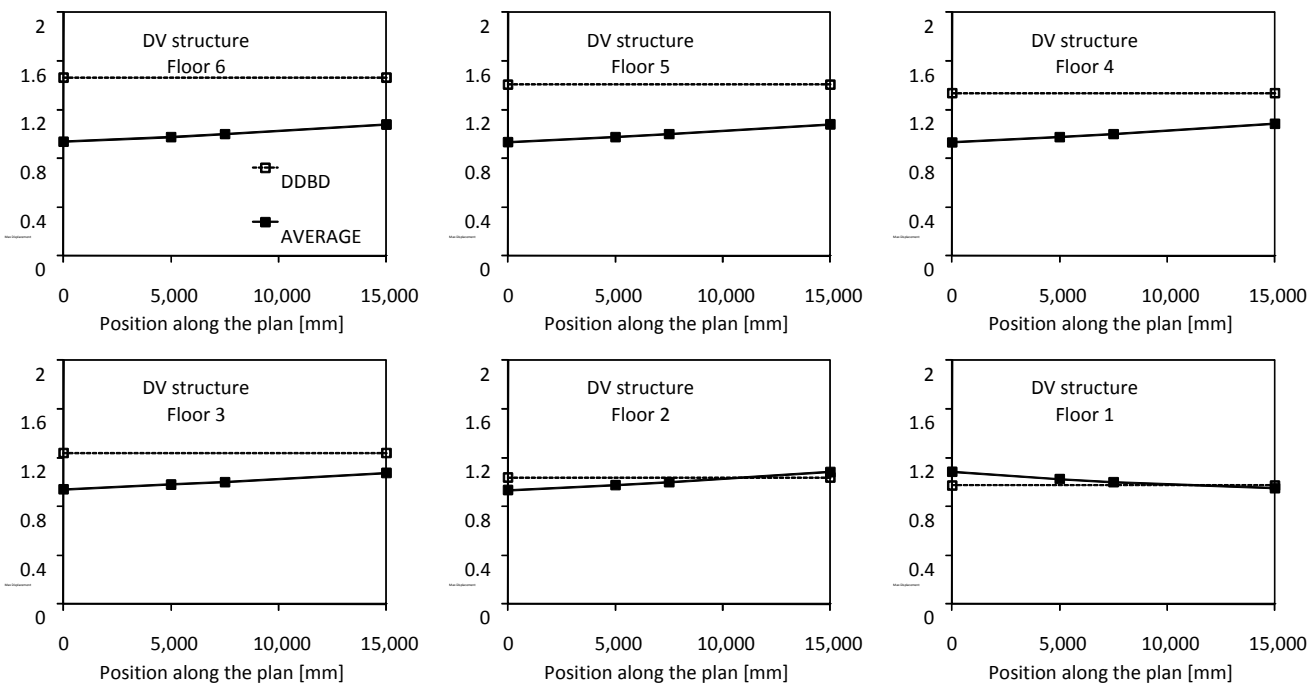

Fig. 9 Envelope of maximum horizontal displacements along the plan for the DV structure. 
Furthermore it has to be noticed that the DV structure is characterized by lower reinforcement ratios in comparison with the EV one. So, as it was expected, the configuration which minimizes the eccentricity is more favourable also in terms of amount of steel used. It is worth mentioning that, since the gravity loads are applied to the frames in the $X$ direction, the frames in the $\mathrm{Z}$ direction are not affected by the presence of the over-strength due to the gravity loads.

\section{Conclusions}

The aim of this research was to include in the displacement-based design the torsional behaviour of frame buildings with plan irregularity. An algorithm was proposed to consider this behavior, and its effectiveness was assessed. Two RC structures characterized by irregular configurations in terms of position of the frames in the plan were studied. One structure was designed allocating the same strength to the frames and obtaining strength and stiffness eccentricity. The other structure was designed in order to eliminate the strength eccentricity. The two structures were then studied by performing nonlinear static and dynamic analyses in order to check the design procedure.

The application of the design procedure resulted simple and useful and the iterations for accounting for plan asymmetry did converge rapidly. The algorithm involved an increase of base shear due to the torsional response of the structure characterized by the same strength of the frames. As a consequence of the increase of base shear, equal to $27 \%$ of the initial value, this structure required more reinforcement quantities. It is evident, therefore, the convenience of reducing as possible in the design phase the strength eccentricity. For both the considered structures a good correspondence between horizontal displacements estimated from analyses and design was found: the average values from nonlinear dynamic analyses resulted slightly lower than design values. A good correspondence between analysis and design was found also for the response of the different frames along the plan. The nonlinear dynamic analyses confirmed, as expected from design, the reduction of the effects of plan-asymmetry for the structure designed in order to eliminate the strength eccentricity, without significant modification of the values of displacements.

\section{References}

[1] G. M. Calvi, Displacement-Based Seismic Design of Reinforced Concrete Buildings, FIB Bulletin 25, Lausanne, 2003.

[2] M. J. N. Priestley, Performance based seismic design, in: Proceedings of the 12th World Conference on Earthquake Engineering, Auckland, New Zealand, 2000.

[3] M. J. N. Priestley, Myths and Fallacies in Earthquake Engineering, Revisited. IUSS Press, Pavia, 2003.

[4] J. D. Pettinga and M. J. N. Priestley, Dynamic Behaviour of Reinforced Concrete Frames Designed with Direct Displacement-Based Design, IUSS Press, Pavia, 2005.

[5] T. J. Sullivan, M. J. N. Priestely and G. M. Calvi, Seismic Design of Frame Wall Structures, ROSE Research Report 2006/02, IUSS Press, Pavia, 2006.

[6] M. J. N. Priestely, G. M. Calvi and M. J. Kowalsky, Displacement-Based Seismic Design of Structures, IUSS Press, Pavia, 2007.

[7] R. Garcia, T. J. Sullivan and G. Della Corte, Development of a displacement-based design method for steel frame-RC wall buildings, Journal of Earthquake Engineering14 (2) (2010) 252-277.

[8] T. J. Maley, T. J. Sullivan and G. Della Corte, Development of a displacement-based design method for steel dual systems with buckling-restrained braces and moment-resisting frames, Journal of Earthquake Engineering 14 (2010) 106-140.

[9] G. M. Calvi and T. J. Sullivan, A Model Code for the Displacement-Based Seismic Design of Structures Draft Subject to Public Enquiry, IUSS Press, Pavia, 2009.

[10] T. Paulay, Some design principles relevant to torsional phenomena in ductile buildings, Journal of Earthquake Engineering 3 (2001) 273-308.

[11] R. Castillo, Seismic design of asymmetric ductile systems, $\mathrm{Ph} . \mathrm{D}$. Thesis, University of Canterbury, Christchurch, New Zealand, 2004.

[12] K. Beyer, Seismic design of torsionally eccentric buildings with RC U-shaped walls, Ph.D. Thesis, Rose School, IUSS Press, Pavia, 2007.

[13] A. Paparo, P. P. Diotallevi and L. Landi, Displacement-based seismic design and analysis of 
plan-asymmetric RC frames, in: Proceedings of the 14th European Conference on Earthquake Engineering, Ohrid, Republic of Macedonia, Aug. 30-Sep. 3, 2010.

[14] F. McKenna and G. L. Fenves, Open System for Earthquake Engineering Simulation, University of California, Berkeley, 2005.

[15] S. Mazzoni, F. McKenna, M. H. Scott and G. L. Fenves, Opensees Command Language Manual, University of California, Berkeley, 2007.

[16] B. D. Scott, R. Park and M. J. N. Priestley, Stress-strain behaviour of concrete confined by overlapping hoops at low and high strain rates, ACI Journal 79 (1) (1982) $13-27$.

[17] A. Benedetti, L. Landi and D. Malavolta, On the design and evaluation of seismic response of RC buildings according to direct displacement-based design approach, in: Proceedings of the 14th World Conference on Earthquake Engineering. Beijing, China, 2008.

[18] E. Faccioli, R. Paolucci and J. Rey, Displacement spectra for long period, Earthquake Spectra 20 (2) (2004) 347-376. 